\title{
PENYEDIAAN AIR BERSIH LAYAK KONSUMSI MENGGUNAKAN KARBON AKTIF SEBAGAI MEDIA FILTRASI
}

\author{
Ika Oksi Susilawati' ${ }^{1)}$, Witiyasti Imaningsih ${ }^{2)}$, Arfan Eko $F^{3)}$ \\ 1)Jurusan Biologi, FMIPA ULM \\ ${ }^{2)}$ Jurusan Fisika, FMIPA ULM \\ Jl. A. Yani, Km 36 , Banjarbaru, Kalimantan Selatan \\ ${ }^{1)}$ Korespondensi penulis, email: ikaoksi_susilawati@unlam.ac.id
}

\begin{abstract}
Abstrak: Air bersih merupakan kebutuhan primer manusia. Desa Sungai Kitano merupakan salah satu desa di Kecamatan Martapura Barat yang masih menggunakan air sungai sebagai sumber air untuk memenuhi kebutuhannya. Untuk mendapatkan air bersih masyarakat melakukan dengan cara konvensional yaitu dengan cara koagulasi dan sedimentasi. Melalui kegiatan PKM dilakukan pengenalan alat penyaring air dengan bahan utama karbon aktif sebagai komponen utama filtrasi. Berdasarkan uji lab yang dilakukan, kualitas air yang telah di saring dengan teknologi membran ultrafiltrasi berdasarkan Kepmenkes No. 907/MENKES/SK/VII/2002 menunjukkan kualitas yang memenuhi kualitas standar air bersih. Satu unit alat penyaring air dengan bahan utama karbon aktif dapat digunakan masyarakat dengan waktu penggantian karbon aktif dan bahan penyaring lainnya sampai 3 tahun, dengan pembersihan 3-4 bulan sekali.
\end{abstract}

Kata Kunci: Sungai Kitano, air bersih, karbon aktif

\section{PENDAHULUAN}

Air merupakan salah satu faktor yang sangat penting bagi kehidupan, karena air digunakan untuk proses memasak, mandi, cuci, dan kakus (MCK). Selain itu, air juga mendukung masyarakat di bidang pertanian.

Ketersediaan air bersih yang cukup di masyarakat merupakan masalah klasik di Indonesia, baik kuantitas maupun kualitasnya. Meningkatnya aktivitas pembangunan dan jumlah penduduk, berakibat pada peningkatan kebutuhan akan air bersih (Wardhana, 2013).

\section{Desa Sungai Kitano Kecamatan} Martapura Barat, merupakan salah satu desa yang memanfaatkan air sungai Martapura untuk memenuhi kebutuhannya. Lokasi desa
Sungai Kitano terletak di pinggir sungai Martapura, sehingga pemenuhan kebutuhan air mengandalkan air sungai Martapura.

Masalah utama dalam pemanfaatan air sungai Martapura adalah pada umumnya sumber air permukaan memiliki kualitas yang kurang baik dan cenderung menurun dari waktu kewaktu akibat pencemaran. Apalagi pada saat musim kemarau, air akan semakin kotor meskipun sudah dilakukan pengendapan dan penggumpalan menggunakan kaporit.

Selain permasalahan air bersih, permasalahan sampah mejadi juga menjadi beban masyarakat desa Sungai Kitano, terutama masalah pembuangan sampah 
keluarga. Untuk membantu mengatasi masalah tersebut tim dosen Fakultas MIPA melalui kegiatan PKM (Program Kemitraan Masyarakat) memperkenalkan penggunaan alat penyaring air sungai dengan karbon aktif sebagai media filtrasi. Kegiatan yang dilakukan meliputi: pengenalan bahan, perakitan alat penyaring, cara penggunaan dan cara perawatan alat penyaring air.

\section{METODE PELAKSANAAN}

Kegiatan PKM dilaksanakan dengan cara penyampaian materi, praktek perakitan, penggunaan, dan perawatan. Khusus untuk pembuatan kompos dilakukan pendampingan sampai mampu membuat kompos dengan benar. Materi penyuluhan disesuaikan dengan bahasa setempat yaitu bahasa Banjar. Pelaksanaan kegiatan dibantu oleh beberapa mahasiswa yang berperan sebagai pendamping pada kegiatan praktek.

\section{HASIL KEGIATAN}

Metode yang efektif digunakan untuk menurunkan unsur-unsur pencemar fisik, kimia, dan biologi salah satunya adalah filtrasi.Filtrasi adalah proses pengolahan air secara fisik untuk menghilangkan partikel padat dalam air dengan melewatkan air tersebut melalui material berpori dengan diameter butiran dan ketebalan tertentu (Rahmawati, 2009).

Adapun media yang digunakan dalam filtrasi antara lain pasir, kerikil, dan karbon aktif. Karbon aktif dipilih karena memiliki sejumlah sifat kimia maupun fisika yang menarik, di antaranya mampu menyerap zat organik maupun anorganik, dapat berlaku sebagai penukar kation, dan sebagai katalis untuk berbagai reaksi (Mifbakhuddin 2010).Susunan bahan filter dalam kegiatan PKM di Sungai Kitano adalah sebagai berikut: pasir silika, zeolite, pasir manganese dan karbon aktif (Gambar 1). Selain itu, karbon aktif mempunyai fungsi untuk menghilangkan bau, warna dan logam berat yang terlarut dalam sampel (Syahputra 2015).

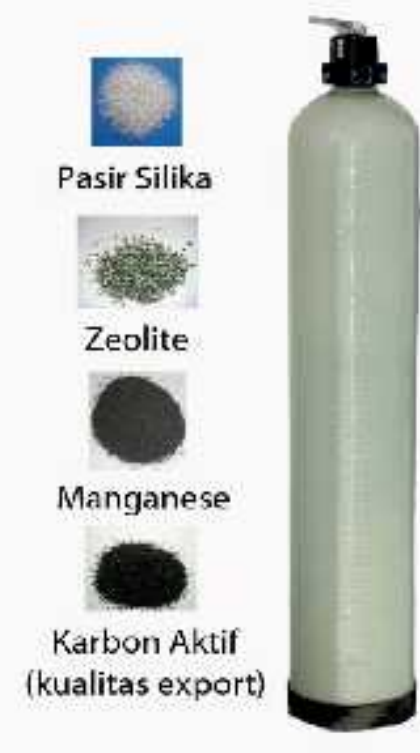

Gambar 1. Tabung penyaring air dan sususan bahan yang berfungsi sebagai filter. 
Model pemasangan penyaring air dengan karbon aktif disajikan pada gambar 3. Berdasarkan gambar 3 tersebut air dari sungai ditampung terlebih dahulu pada tandon penampung, berikutnya dialirkan ke alat penyaring, setelah itu dialirkan ke tandon penampung air bersih. Model pemasangan seperti pada Gambar 3. bertujuan untuk memperpanjang umur bahan penyaring yang ada di dalam tabung termasuk karbon aktifnya. Dengan model seperti pada Gambar 3, perbersihan alat penyaring dapat dilakukan 1 tahun sekali. Namun jika tanpa tandon penampung, artinya air dari sungai langsung dimasukkan ke alat penyaring, pembersihan dilakukan 3-4 bulan sekali.

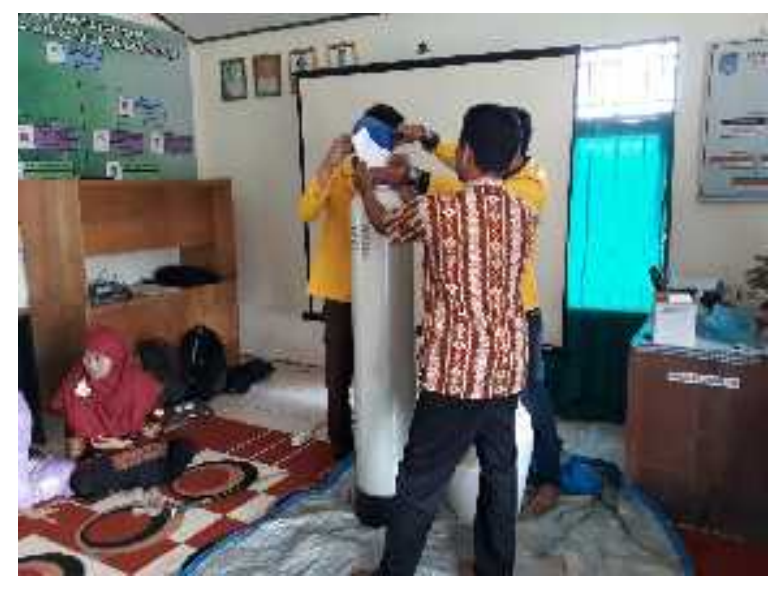

Gambar 2. Proses pengisian bahan filter pada tabung penyaring

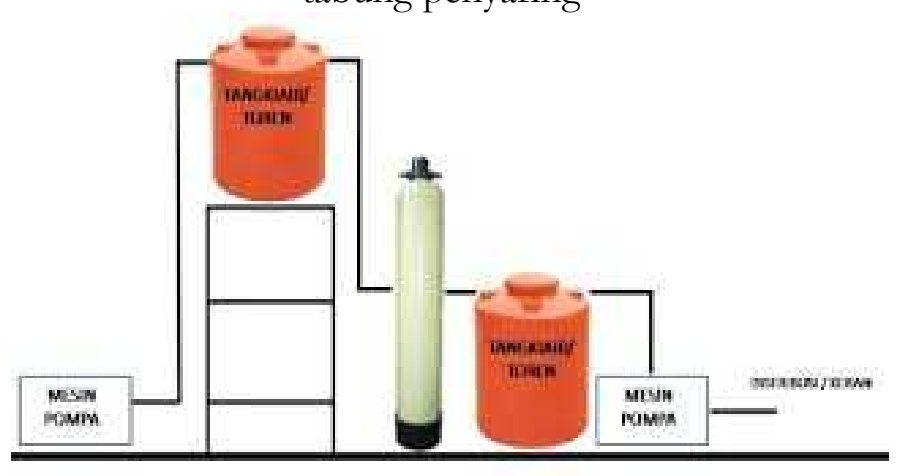

Gambar 3. Model pemasangan filter dengan karbon aktif.

Uji laboratorium juga dilakukan terhadap air yang belum dan sudah di lakukan penyaringan (Tabel 1). Berdasarkan tabel 1. Air yang dihasilkan melalui penyaringan masih sesui dengan standar Kepmenkes No. 907/ MENKES/SK/VII/2002. Hal ini menunjukkan bahwa terdapat perbaikan kualitas air yang yang telah dilakukan penyaringan menggunakan penyaring kabon aktif, sehingga layak di gunakan untuk memenuhi kebutuhan air bersih

Tabel 1. Hasil uji kualitas air

\begin{tabular}{|c|c|c|c|c|c|}
\hline No & $\begin{array}{l}\text { Indika } \\
\text { tor }\end{array}$ & $\begin{array}{c}\text { Sebelu } \\
\text { m }\end{array}$ & $\begin{array}{c}\text { Sesu } \\
\text { dah }\end{array}$ & $\begin{array}{c}\text { Stan } \\
\text { dar }\end{array}$ & $\begin{array}{c}\text { Satu } \\
\text { an }\end{array}$ \\
\hline 1 & $\begin{array}{l}\text { Keker } \\
\text { uhan }\end{array}$ & 105 & 1 & $\begin{array}{c}\text { Maks } \\
.5\end{array}$ & $\begin{array}{c}\text { NT } \\
\mathrm{U}\end{array}$ \\
\hline 2 & $\mathrm{pH}$ & 5,78 & 6,38 & $6-9$ & - \\
\hline 3 & TSS & 148 & 10 & $\begin{array}{c}\text { Maks } \\
.50\end{array}$ & $\begin{array}{c}\mathrm{mg} / \\
\mathrm{L}\end{array}$ \\
\hline 4 & Suhu & 28 & 27 & $\begin{array}{c}\text { Suhu } \\
\text { udar } \\
\mathrm{a}+ \\
3^{\circ} \mathrm{C}\end{array}$ & C \\
\hline 5 & TDS & 289 & 77 & $\begin{array}{c}\text { Maks } \\
\cdot \\
1000\end{array}$ & $\begin{array}{c}\mathrm{mg} / \\
\mathrm{L}\end{array}$ \\
\hline 6 & Rasa & $\begin{array}{c}\text { Tida } \\
\mathrm{k} \\
\text { beras } \\
\text { a }\end{array}$ & $\begin{array}{c}\text { Tidak } \\
\text { beras } \\
\text { a }\end{array}$ & $\begin{array}{c}\text { Tida } \\
\mathrm{k} \\
\text { beras } \\
\text { a }\end{array}$ & \\
\hline
\end{tabular}




\title{
KESIMPULAN
}

\author{
Penggunaan alat penyaring \\ menggunakan karbon aktif dapat \\ menghasilkan air yang bersih dan layak \\ konsumsi. Selain itu perawatannya sangat \\ mudah dan mempunyai waktu pakai yang lama. \\ Proses pembersihan alat penyaring dapat \\ dilakukan 6-8 bulan sekali, sedangkan \\ penggantian karbon aktif dapat dilakukan 3 \\ tahun sekali.
}

\section{DAFTAR PUSTAKA}

Mifbakhuddin, 2010. Pengaruh Ketebalan Karbon Aktif Sebagai Media Filter Terhadap Penurunan Kesadahan Air sumur artetis. Jurnal Eksplanasi, Vol 5 No. 2.

Rahmawati A. 2009. Efisiensi Filter Pasir Zeolit dan Filter Pasir Arang Tempurung Kelapa Dalam rangkaian Unit Pengolahan Air Untuk Mengurangi kandungan Mangan dari Dalam Air. Seminar Internasional Hasil-hasil Peenelitian Jurusan Pendidikan Teknik dan Kejuruan FKIP universitas Sebelas maret

Syahputra A, Sugianto, Syech R. 2015. Rancang Bangun Alat Penjernih Air Yang Tercemar Logam Berat Fe, Cu, Zn Dalam Skala Laboratorium. Jom Fmipa Volume 2 No. 1 Februari 2015.

Wardhana I.W., Budiharjo M..A., Adhesti S., 2013. Kajian Sistem Penyediaan Air Bersih Sub Sistem Bribin Kabupaten Gunungkidul. Jurnal Presipitasi. 10(1):18-29 